\title{
Lipid Accumulation Product: Reliable Marker for Cardiovascular Risk Detection?
}

\author{
Lidiane Aparecida Vila Pires ${ }^{1}$, Ricardo José Tofano1,2,3, Sandra Maria Barbalho1,2,4,5* $\mathbb{}$, \\ Claudia Rucco Penteado Detregiachi, ${ }^{1,2,5}$, Marcelo Dib Bechara', \\ Viviane Alessandra Capelluppi Tofano ${ }^{1}$, Jesselina Francisco dos Santos Haber ${ }^{1,5}$, \\ Eduardo Federighi Baisi Chagas²,5, Ana Maria Gonçalvez Milla², Karina Quesada1
}

${ }^{1}$ School of Medicine, University of Marília (UNIMAR), Marília, São Paulo, Brazil

${ }^{2}$ Postgraduate Program in Structural and Functional Interactions in Rehabilitation, University of Marilia (UNIMAR), São Paulo, Brazil

${ }^{3}$ Cardiology Unit of the UNIMAR Beneficent Hospital (HBU), Marilia, São Paulo, Brazil

${ }^{4}$ Department of Biochemistry and Nutrition, Faculty of Food Technology of Marília, Marília, São Paulo, Brazil

${ }^{5}$ CENID (Interdisciplinary Center on Diabetes)_UNIMAR_Marília, São Paulo, Brazil

Email: *smbarbalho@gmail.com

How to cite this paper: Pires, L.A.V., Tofano, R.J., Barbalho, S.M., Detregiachi, C.R.P., Bechara, M.D., Tofano, V.A.C., Haber, J.F. dos S., Chagas, E.F.B., Milla, A.M.G. and Quesada, K. (2021) Lipid Accumulation Product: Reliable Marker for Cardiovascular Risk Detection?. Open Journal of Epidemiology, 11, 267-277.

https://doi.org/10.4236/ojepi.2021.113023

Received: April 20, 2021

Accepted: July 27, 2021

Published: July 30, 2021

Copyright $\odot 2021$ by author(s) and Scientific Research Publishing Inc. This work is licensed under the Creative Commons Attribution International License (CC BY 4.0).

http://creativecommons.org/licenses/by/4.0/ (c) (i) Open Access

\begin{abstract}
The Lipid Accumulation Product (LAP) is a clinical marker of visceral obesity and has been proposed as a simple, inexpensive, and accurate tool to estimate cardiovascular risk and mortality. The aim of this study was to verify the association of LAP with anthropometric, biochemical, visceral adiposity index and IR in adults and the elderly. This single cross-section center clinical study, with experimental, analytical, primary, and observational design, included 210 participants. Anthropometric (Body Mass Index (BMI), Waist Circumference (WC), and Neck Circumference (NC)), LAP, Visceral Adipose Index (VAI), and biochemical parameters (fasting glycemia, insulinemia (to calculate the Homa-IR index), total cholesterol, LDL-c, HDL-c, and triglycerides) were evaluated. The results showed that by separating the sample into three groups (adequate BMI and WC, adequate BMI and elevated WC, and elevated BMI and WC), the group with high BMI and WC showed a high value of LAP and VAI compared to the other groups, with a significant difference. Still, the data show a positive and significant correlation when relating the LAP with VAI, HOMA-IR, BMI, WC, NC, total cholesterol, triglycerides, and Diastolic Blood Pressure. It also showed an inversely proportional relationship when associating LAP with HDL-c $(\mathrm{p}<0.0001)$. Thus, we show that LAP is closely related to visceral adiposity, IR, altered lipid parameters, and blood pressure, especially diastolic in the patients included in our study. For these reasons, we suggest that LAP is a reliable indicator of promising visceral adiposity for early detection of cardiovascular risk in the adult and senior population.
\end{abstract}




\section{Keywords}

Lipid Accumulation Product, Obesity. Visceral Obesity, Metabolic Syndrome, Cardiovascular Risk

\section{Introduction}

Obesity is a significant risk factor for many conditions, such as metabolic syndrome (MS) and cardiovascular disease (CVD). It is the leading cause of avoidable death in the world [1] [2]. Excess of intra-abdominal or visceral fat is directly associated with insulin resistance (IR) pathogenesis and CVD development, relating more strongly to metabolic abnormalities than total and subcutaneous body adiposity [3] [4].

The Lipid Accumulation Product (LAP) is a clinical marker of visceral obesity and has been proposed as a simple, inexpensive, and accurate tool to estimate cardiovascular risk and mortality. It combines anthropometric parameters and metabolic variables as effective and reliable markers also to predict MS since the gold standard methods for evaluating visceral fat are expensive, and the measurement of waist circumference (WC) alone does not distinguish between subcutaneous and visceral fat [5] [6] [7].

Therefore, LAP was suggested as a reliable marker also for IR [8] [9]; since hyperinsulinemic-euglycemic clamp test is time-consuming and expensive, and the HOMA-IR (most frequently used validated marker) may present difficulties since the plasma insulin levels are challenging to measure [10].

This study aimed to verify the association of LAP with anthropometric, biochemical, visceral adiposity index and IR in adults and the elderly.

\section{Methods}

This study started only after the approval of the Research Ethics Committee of the University of Marilia/SP under Protocol number 4035366 on May 19, 2020, according to the Ethical and Legal requirements for research with human beings, as established by the National Health Council. Moreover, this study was has been carried out in accordance with The Code of Ethics of the World Medical Association (Declaration of Helsinki).

Data collection was performed from data obtained in patient medical records. All medical records of adult and elderly patients of both sexes were included, which contained all the variables necessary for the study. We included patients that performed biochemical and anthropometric evaluation in the three last months. Medical records of pregnant women, lactating women, and patients with chronic kidney disease, disabsorptive diseases and who underwent bariatric surgery were excluded.

This is a single cross-section center clinical study with exploratory, analytical, primary, and observational design. The research was conducted with 210 adult 
and elderly patients from a private cardiology clinic and the Cardiology Medical Clinic of a University Hospital from a city in São Paulo State. Patients aged between 20 and 90 years were included. Data collection was carried out from June 2020 to January 2021.

Besides personal identification data (name, gender, and age), information on the previous diagnosis of diseases or clinical conditions, continuous use of medication, smoking, and consumption of alcoholic beverages were collected.

For the nutritional diagnosis, weight and height were collected, and the body mass index (BMI) was calculated, plus WC and neck circumference (NC) measurements to determine metabolic risk. The anthropometric measurements were measured and recorded by trained professionals according to the techniques recommended by GIBSON [11].

BMI was assessed based on the World Health Organization [12], namely: low weight $\left(<18.5 \mathrm{~kg} / \mathrm{m}^{2}\right)$, adequate weight $\left(\geq 18.5 \mathrm{~kg} / \mathrm{m}^{2}\right.$ and $\left.<25 \mathrm{~kg} / \mathrm{m}^{2}\right)$, overweight $\left(\geq 25 \mathrm{~kg} / \mathrm{m}^{2}\right.$ and $\left.<30 \mathrm{~kg} / \mathrm{m}^{2}\right)$ and obesity $\left(\geq 30 \mathrm{~kg} / \mathrm{m}^{2}\right)$. The categorization of metabolic risk based on the measurement of WC was carried out following the cut-off points also proposed by the World Health Organization [12]: normal or no risk ( $<80 \mathrm{~cm}$ for women; and $<94 \mathrm{~cm}$ for men), high risk $(80 \geq \mathrm{WC}<88 \mathrm{~cm}$ for women; and $94 \geq \mathrm{WC}<102 \mathrm{~cm}$ for men) and very high risk ( $\geq 88 \mathrm{~cm}$ for women; and $\geq 102 \mathrm{~cm}$ for men). Subsequently, patients were divided into 3 groups: individuals with adequate BMI and WC, adequate BMI and elevated WC and elevated BMI and WC.

The NC was measured in the average neck height and men just below the laryngeal prominence, with the individual standing, facing the assessor, with the shoulders relaxed [13]. The classification of this measure was based on Stabe et al. [14], which propose a cut-off points value greater than $39.6 \mathrm{~cm}$ in men and greater than $36.1 \mathrm{~cm}$ in women being associated with higher metabolic risk

Data were also collected on blood pressure (BP) and biochemical parameters of fasting glycemia, insulinemia (to calculate the Homa-IR index), total cholesterol, LDL-c, HDL-c, and triglycerides.

The LAP was calculated using a formula for women (waist circumference $[\mathrm{cm}]-58) \times($ triglycerides $[\mathrm{mmol} / \mathrm{L}])$ and for men (waist circumference $[\mathrm{cm}]-65)$ $\times$ (triglycerides [mmol/L]) [15]. In order to convert this unit of measurement of triglycerides into milligrams per deciliter $(\mathrm{mg} / \mathrm{dL})$ to adapt the formula for calculating the LAP index, it was necessary to divide the result obtained in the individual tests of each participant by 88.5 [16].

LAP is estimated by the relationship between triglyceride serum concentrations and WC, becoming an alternative measure of excess lipids accumulated at the waist [17] [18].

The visceral adiposity index (VAI) calculation was performed from the formula proposed by Amato et al. [19]. The formula is composed of two anthropometric measurements $\left(\mathrm{BMI}\right.$ in $\mathrm{Kg} / \mathrm{m}^{2}$ and $\mathrm{WC}$ in $\mathrm{cm}$ ) and two metabolic parameters (HDL-c and TG in mmol/L). For males: $\mathrm{VAI}=(\mathrm{WC} / 39.68+(1.88 \times$ $\mathrm{BMI})) \times(\mathrm{TG} / 1.03) \times(1.31 / \mathrm{HDL})$ and for females: $\mathrm{VAI}=(\mathrm{WC} / 36.58+(1.89 \times$ 
$\mathrm{BMI})) \times(\mathrm{TG} / 0.81) \times(1.52 / \mathrm{HDL})$.

For the evaluation of insulin resistance, the Homeostasis Model Assessment of Insulin Resistance Index (HOMA-IR) was calculated.

The statistical treatment of quantitative data was performed with the support of the BioEstat 5.0 program. The data were presented in tables of frequency or mean \pm standard deviation and median. To evaluate the significance, association, and correlation of the variables studied, appropriate tests such as Kruskall-Wallis and Pearson correlation were used. The probability of significance considered was $5 \%(\mathrm{p}<0.05)$ for the operations performed.

\section{Results}

We included 210 patients, $53.81 \%$ male and $46.19 \%$ female, whose mean age was $56.9 \pm 13.51$ years (minimum 21 years and maximum 87 years). Of this total, we divided into three groups: patients with adequate BMI and $\mathrm{WC}(\mathrm{n}=33$ patients, $15.71 \%$ of the sample); patients with adequate BMI and high WC ( $\mathrm{n}=21$ patients, $10 \%$ of the sample) and patients with high BMI and WC (n = 156 patients, $74.29 \%$ ).

There was male predominance in patients with adequate BMI and (72.73\%) and elevated BMI and WC (51.92\%). On the other hand, there was a female predominance in the group with adequate BMI and elevated WC (61.90\%).

Within these groups, a predominance of pre-existing clinical diseases was noted, such as type 2 diabetes mellitus, CVD, dyslipidemia, and hypertension in the group of adequate BMI and elevated WC.

There was a statistical significance when analyzing the age of patients between such groups (data not shown). Patients with high BMI and WC have a lower average age $(\mathrm{p}<0.001)$.

When checking the lipid profile between the three groups, a statistical significance was found for the HDL-c and TG. As the BMI and WC increase, the lower the HDL-c fraction and the higher the plasma TG (Table 1).

Table 1. Comparison between the three groups with the lipid profile.

\begin{tabular}{|c|c|c|c|c|c|c|c|c|c|c|c|c|c|}
\hline & \multicolumn{4}{|c|}{$\begin{array}{c}\text { Adequate BMI } \\
\text { and WC }(n=33)\end{array}$} & \multicolumn{4}{|c|}{$\begin{array}{l}\text { Adequate BMI and } \\
\text { elevated WC }(n=21)\end{array}$} & \multicolumn{4}{|c|}{$\begin{array}{c}\text { Elevated BMI and } \\
\text { WC }(n=156)\end{array}$} & \multirow[t]{2}{*}{ p-value } \\
\hline & Mean & SD & Median & $\%$ & Mean & SD & Median & $\%$ & Mean & $\mathrm{SD}$ & Median & $\%$ & \\
\hline $\begin{array}{c}\mathrm{TC} \\
(\mathrm{mg} / \mathrm{dl})\end{array}$ & 189.06 & 44.21 & 187 & 63.64 & 189.63 & 51.58 & 185 & 57.14 & 187.49 & 47.4 & 189.5 & 64.74 & $0.9944^{\star}$ \\
\hline $\begin{array}{c}\mathrm{LDL} \\
(\mathrm{mg} / \mathrm{dl})\end{array}$ & 112.05 & 40.77 & 112 & 27.27 & 114.29 & 43.37 & 111 & 33.33 & 113.25 & 40.37 & $7 \quad 113.6$ & 35.26 & $0.8962^{\star}$ \\
\hline $\begin{array}{c}\text { HDL } \\
(\mathrm{mg} / \mathrm{dl})\end{array}$ & 53.62 & 14.82 & 51 & 33.33 & 46.72 & 14.12 & 45.4 & 47.62 & 44.79 & 13.65 & $\begin{array}{ll}5 & 43.5\end{array}$ & 56.41 & $0.0034^{\star}$ \\
\hline $\begin{array}{c}\mathrm{TG} \\
(\mathrm{mg} / \mathrm{dl})\end{array}$ & 121.26 & 68.3 & 106 & 39.39 & 143.26 & 73.5 & 108 & 47.62 & 155 & 71.1 & 146 & 57.05 & $0.0173^{\star}$ \\
\hline
\end{tabular}

BMI: Body Mass Index; WC: Waist Circumference; TC: Total cholesterol; TG: triglycerides; SD: Standard Deviation. ${ }^{\star}$ Kruskal-Wallis. 
Observing the LAP, VAI, and HOMA-IR, it was found that all the indexes had a difference when comparing the three groups (Table 2). The values of LAP, VAI, and HOMA-IR increase the greater the WC and BMI.

The correlation of LAP with VAI and HOMA-IR showed that both are directly proportional and with a statistical significance, that is, that when the values increase, the tendency is that the LAP also increases (Figure 1). Being that $70 \%$ ( $\mathrm{r} 2$ ) of the variation of VAI is explained by the variation of the LAP and 13\% (r2) of the variation of the HOMA-IR is explained by the variation of the LAP, considered excellent and moderate, respectively. It was also seen that by correlating BMI, WC, and NC with LAP, all were directly proportional to LAP and

Table 2. Comparison between the three groups with LAP, VAI, and HOMA-IR.

\begin{tabular}{ccccccccccccc}
\hline & \multicolumn{2}{c}{$\begin{array}{c}\text { Adequate BMI and } \\
\text { WC }(\mathrm{n}=33)\end{array}$} & \multicolumn{2}{c}{$\begin{array}{c}\text { Adequate BMI and } \\
\text { elevated WC }(\mathrm{n}=21)\end{array}$} & \multicolumn{2}{c}{$\begin{array}{c}\text { Elevated BMI and } \\
\text { WC }(\mathrm{n}=156)\end{array}$} & p-value \\
\cline { 2 - 12 } & Mean & SD & Median & Mean & SD & Median & Mean & SD & Median & \\
\hline LAP & 26.27 & 2.68 & 22.31 & 53 & 30.36 & 45.15 & 81.09 & 43.7 & 70.75 & $<0.0001^{*}$ \\
VAI & 205.84 & 137.9 & 158.18 & 314.68 & 210.62 & 213.45 & 438.1 & 268.61 & 397.03 & $<0.0001^{*}$ \\
HOMA-IR & 1.96 & 1.18 & 1.79 & 2.59 & 2.51 & 1.77 & 3.9 & 2.96 & 3.02 & $<0.0001^{*}$ \\
\hline
\end{tabular}

BMI: Body Mass Index; WC: Waist Circumference; SD: Standard Deviation; LAP: Lipid Accumulation Product; VAI: Visceral Adiposity Index; HOMA-IR: Homeostasis model assessment for insulin resistance. ${ }^{\star}$ Kruskal-Wallis.

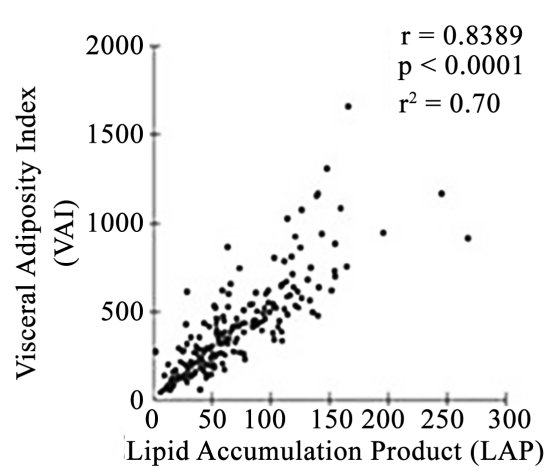

(a)

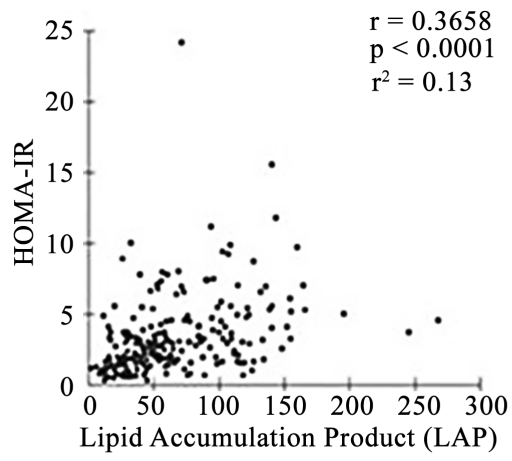

(b)

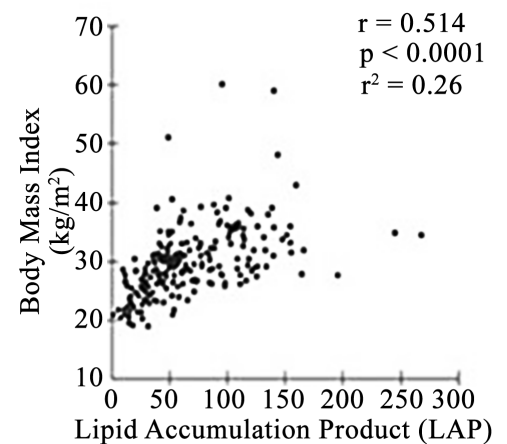

(c)

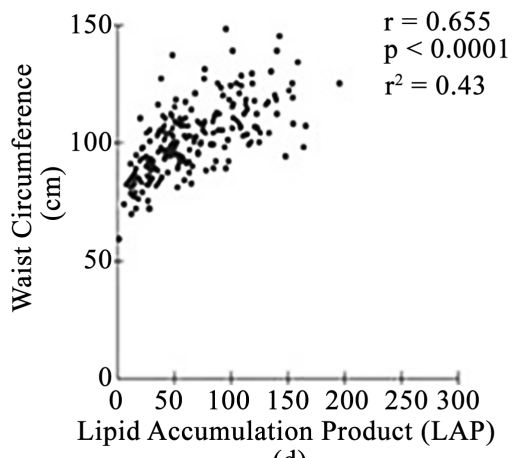

(d)

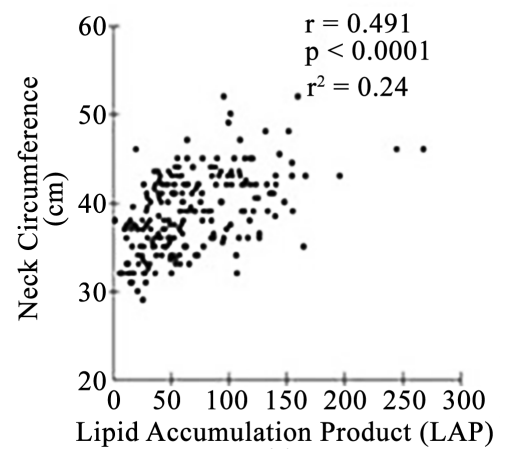

(e)

Figure 1. Correlation between visceral adiposity index, HOMA-IR, body mass index, waist circumference, and neck circumference with the lipid accumulation product. (a) Visceral adiposity index and lipid accumulation product; (b) HOMA-IR and lipid accumulation product. 
with p-value $<0.0001$ (Figure 1), according to the $\mathrm{r} 2$ value, $26 \%$ of the BMI variation, $43 \%$ of the WC variation and $24 \%$ of the NC variation are explained by the LAP variation, considered moderate, good and moderate, respectively.

By correlating the lipid profile with the LAP, it was observed that the total cholesterol and triglycerides are directly proportional and with statistical significance to the LAP. When comparing LDL-c, although it was seen to be directly proportional to LAP, it was not shown to have a significant difference. HDL-c values, with a statistic significance, showed that it is inversely proportional, suggesting that when the values of HDL-c increase, the LAP tends to decrease, and vice versa (Figure 2). Being 12\% (moderate) the explanatory power of the $\mathrm{HDL}-\mathrm{c}$ variation in relation to the LAP variation.

By correlating the LAP with systolic blood pressure (SBP) and diastolic blood pressure (DBP), it was observed that both are directly proportional to the increase of the LAP, but a statistical significance was only obtained in the correlation with the DBP (Figure 3).

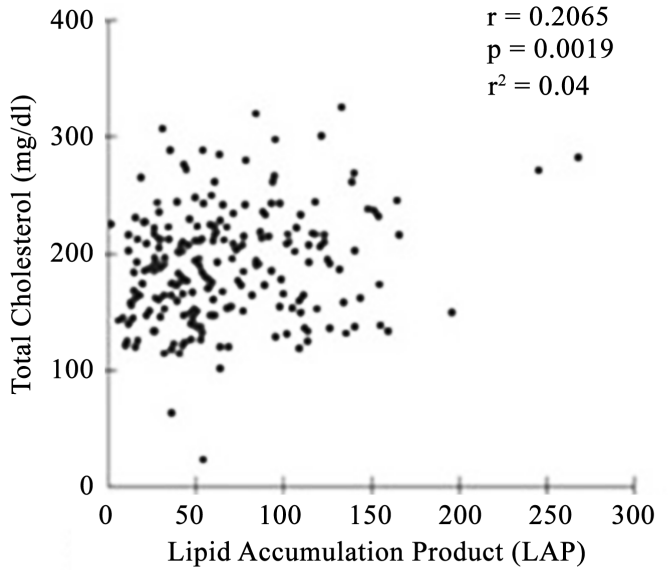

(a)

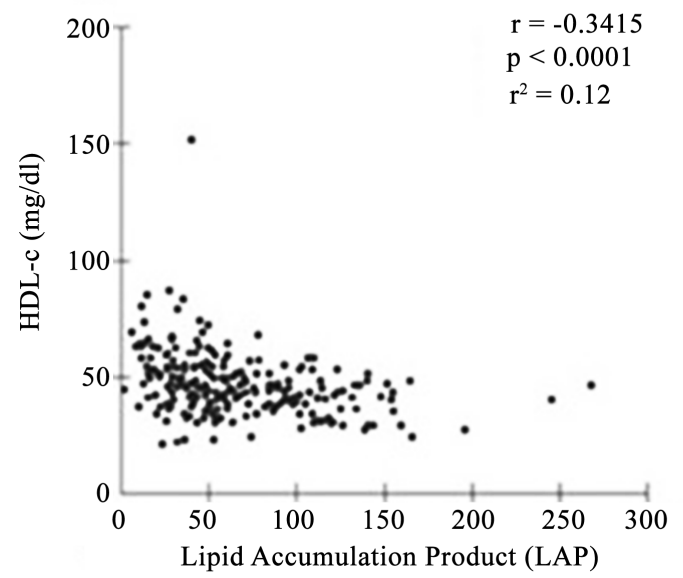

(c)

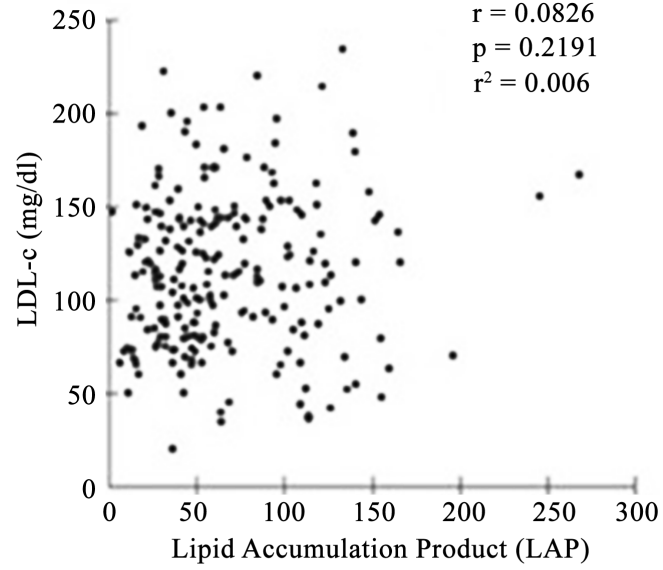

(b)

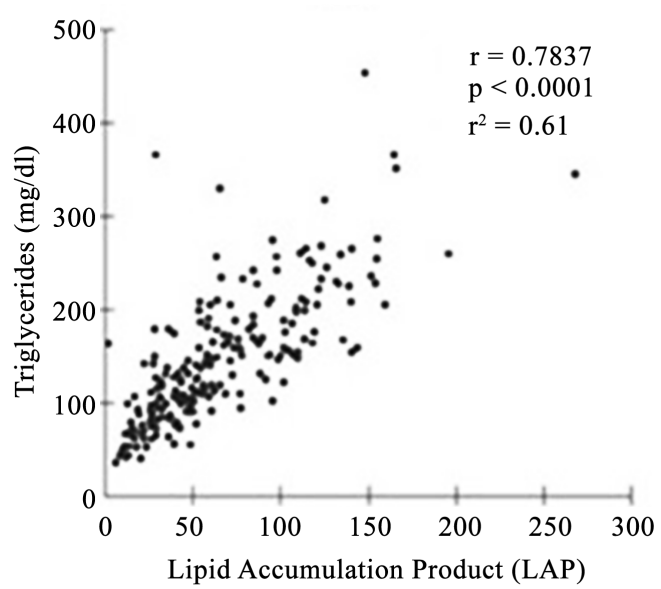

(d)

Figure 2. Correlation between total cholesterol, LDL-c, HDL-c, and triglycerides with the lipid accumulation product. (a) Total cholesterol and lipid accumulation product; (b) LDL-c and lipid accumulation product; (c) HDL-c and lipid accumulation product; (d) Triglycerides and lipidic accumulation product. 


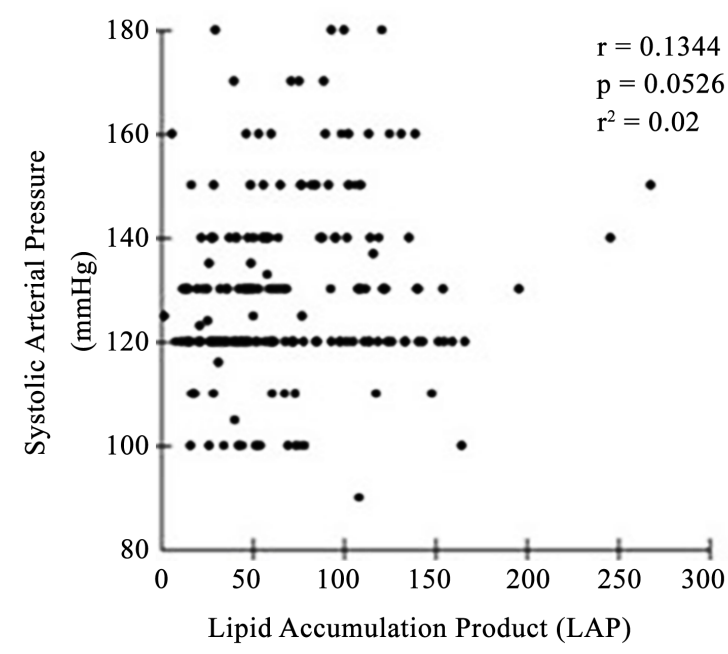

(a)

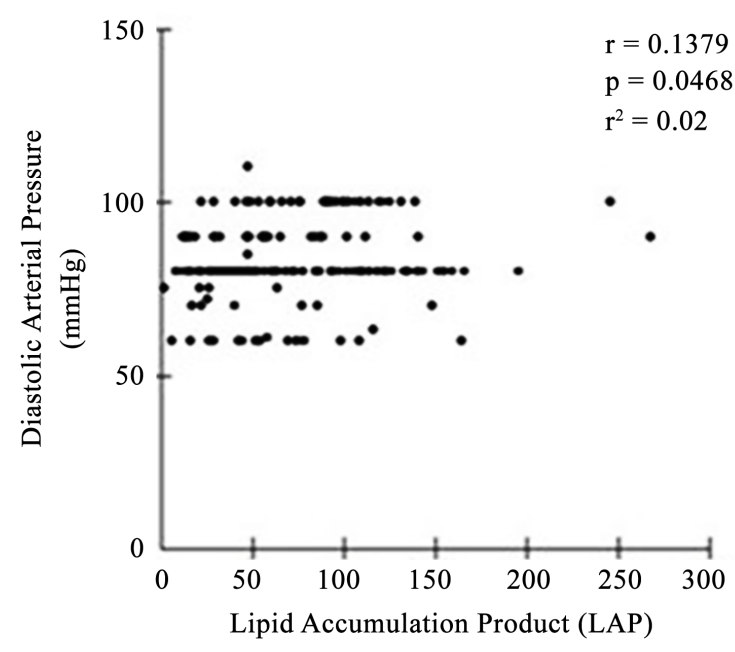

(b)

Figure 3. Correlation between systolic and diastolic blood pressure with the lipid accumulation product. (a) Systolic arterial pressure and lipid accumulation product; (b) Diastolic arterial pressure and lipid accumulation product.

\section{Discussion}

This study showed that, by separating the sample into three groups, the group with high BMI and WC showed a high LAP and VAI value compared to the other groups, with a statistical significance. Still, the data show a positive and significant correlation when relating the LAP with VAI, HOMA-IR, BMI, WC, NC, total cholesterol, triglycerides, and DBP. It also showed an inversely proportional relationship when associating LAP with HDL-c $(\mathrm{p}<0.0001)$. Thus, we show that LAP is closely related to visceral adiposity, IR, altered lipid parameters, and blood pressure, especially diastolic.

Abruzzeze et al. showed that in women with Polycystic Ovary Syndrome, the LAP and VAI index proved to be good markers of cardiovascular risk factors associated with insulin resistance (HOMA-IR) [20].

Pineda et al. [21], in a cross-sectional study with MS patients, found that LAP values for men in the group without MS were 13.9 - 21.7, and for women were 10.6 and 21.27. For men with MS, the values were between $59.79-112.19$ and 41.29 - 87.69 for women; in the group with CVD, the male individuals presented values of $59-101.13$, and between 45.47 and 68.47 in the female group. With these results, the authors could determine a relationship between LAP and VAI with cardiometabolic risk in subjects with and without MS ( $p<0.005)$.

In another cross-sectional study [15], the authors showed that LAP has a significant association with cardiovascular biomarkers, but these associations were especially important when LAP was correlated to LDL-c and HDL-c. Similarly, our study showed a directly proportional relationship but without a significant difference when associating LAP with LDL-c and an inversely proportional relationship ( $\mathrm{p}<0.0001)$ when relating LAP with HDL-c.

Ilhan et al. [22] evaluated the visceral adiposity indicators as predictors of MS in postmenopausal women, and found a positive correlation when relating LAP 
with VAI, BMI, triglycerides, systolic and diastolic blood pressure (all with $\mathrm{p}<$ 0.05); besides finding a positive comparison between LAP and total cholesterol, and LAP with LDL-c, but not significant. In contrast, there was a negative and significant correlation between LAP and HDL-c (p-value lower than 0.01). Our study showed similar results when associating these variables. The only differences were that when correlating the SBP with LAP, there was no significant difference, and when comparing the LAP with total cholesterol, it is possible to see a directly proportional relationship and a significant difference. Therefore, LAP can be a superior marker of IR and cardiovascular risk compared to lipid ratios (total cholesterol/HDL-c) and triglycerides/HDL-c [20].

Other authors showed that LAP is related to several conditions. Rotter et al. [23] showed that subjects with obesity, MS, and DM2, present a significantly higher LAP than subjects without these conditions. These authors also found a positive and significant correlation with glycemia, total cholesterol, insulin, and a negative correlation with HDL-c. Guo et al. [24] also investigated the correlation of LPA and metabolic parameters and found that this index is a useful indicator for diagnosing and screening MS.

Our study showed, with a significant difference, that LAP is directly related to WC. Similarly, Soares [25] found that the LAP is directly related to WC $(r=0$. 611 and $\mathrm{p}<0.001)$, DBP $(\mathrm{r}=0.369$ and $\mathrm{p}<0.001)$, and triglycerides $(\mathrm{r}=0.946$ and $\mathrm{p}<0.001)$; however, there was an inversely proportional correlation of LAP with HDL-c $(r=-0.288$ and $\mathrm{p}<0.001)$.

In summary, this study showed a reliable association between LAP and the biochemical, anthropometric, and insulin resistance variables, showing that it is a reliable indicator of promising visceral adiposity for early detection of cardiovascular risk in the adult and senior population. The use of variables that can assess early cardiometabolic risk is an essential strategy for preventing cardiovascular and metabolic diseases.

The limitations of our study are that the sample has similar clinical characteristics in terms of the presence of chronic non-transmissible diseases and may alter the results when applied to samples with healthy individuals or other pathologies. Statistical analyzes were performed without considering gender and age group.

\section{Acknowledgements}

We are grateful to Hospital Beneficente da UNIMAR, Marília, São Paulo, Brazil, for the partnership to carry out this study.

\section{Authors Contribution}

Conceptualization, Methodology, Software, Resources, Writing-original draft: LAVP, RJT, JFSH and KQ. Conceptualization, Resources, Data curation: SMB, MDB, VACT and CRPD. Supervision, Validation, Writing-review \& editing: LAVP, RJT, KQ, and SMB. 


\section{Conflicts of Interest}

The authors declare no conflict of interest.

\section{References}

[1] Irakoze, L., Manirakiza, A., Zhang, Y., Liu, J., Li, J., Nkengurutse, L., et al. (2021) Metabolic Syndrome in Offspring of Parents with Metabolic Syndrome: A Meta-Analysis. Obesity Facts, 14, 148-162. https://doi.org/10.1159/000513370

[2] Lai, C.Q., Parnell, L.D., Smith, C.E., Guo, T., Sayols-Baixeras, S., Aslibekyan, S., et al. (2020) Carbohydrate and Fat Intake Associated with Risk of Metabolic Diseases through Epigenetics of CPT1A. The American Journal of Clinical Nutrition, 112, 1200-1211. https://doi.org/10.1093/ajcn/nqaa233

[3] Ezeh, U., Pall, M., Mathur, R., Dey, D., Berman, D., Chen, I.Y., et al. (2013) Effects of Endogenous Androgens and Abdominal Fat Distribution on the Interrelationship between Insulin and Non-Insulin-Mediated Glucose Uptake in Females. The Journal of Clinical Endocrinology and Metabolism, 98, 1541-1548.

https://doi.org/10.1210/jc.2012-2937

[4] Huang, W., Shu, L., Zhao, H., Chen, S., Zhang, H. and Song, G. (2020) Association of the Triglyceride to High-Density Lipoprotein Ratio and the Visceral Adiposity Index with Metabolic Syndrome in Diabetic Susceptible Population. Hormone and Metabolic Research, 52, 95-103. https://doi.org/10.1055/a-1089-7991

[5] Long, J., Li, L., Wang, F., Yang, G., Cheng, W., Wei, J., et al. (2019) Screening for a Simple and Effective Indicator of Insulin Resistance in Chinese Reproductive-Aged Women, with the Insulin Clamp Technique as a Reference. Metabolic Syndrome and Related Disorders, 17, 423-429. https://doi.org/10.1089/met.2019.0019

[6] Zhang, K., Li, Q., Chen, Y., Wang, N. and Lu, Y. (2017) Visceral Adiposity and Renal Function: An Observational Study from SPECT-China. Lipids in Health and Disease, 16, 205. https://doi.org/10.1186/s12944-017-0597-0

[7] Glintborg, D., Petersen, M.H., Ravn, P., Hermann, A.P. and Andersen, M. (2016) Comparison of Regional Fat Mass Measurement by Whole Body DXA Scans and Anthropometric Measures to Predict Insulin Resistance in Women with Polycystic Ovary Syndrome and Controls. Acta Obstetricia et Gynecologica Scandinavica, 95, 1235-1243. https://doi.org/10.1111/aogs.12964

[8] Xia, C., Li, R., Zhang, S., Gong, L., Ren, W., Wang, Z., et al. (2012) Lipid Accumulation Product Is a Powerful Index for Recognizing Insulin Resistance in Non-Diabetic Individuals. European Journal of Clinical Nutrition, 66, 1035-1038.

https://doi.org/10.1038/ejen.2012.83

[9] Er, L.-K., Wu, S., Chou, H.-H., Hsu, L.-A., Teng, M.-S., Sun, Y.-C., et al. (2016) Triglyceride Glucose-Body Mass Index Is a Simple and Clinically Useful Surrogate Marker for Insulin Resistance in Nondiabetic Individuals. PLos ONE, 11, e0149731. https://doi.org/10.1371/journal.pone.0149731

[10] Kang, B., Yang, Y., Lee, E., Yang, H., Kim, H., Lim, S., et al. (2017) Triglycerides/Glucose Index Is a Useful Surrogate Marker of Insulin Resistance among Adolescents. International Journal of Obesity, 41, 789-792. https://doi.org/10.1038/ijo.2017.14

[11] Gibson, R.S. (2005) Principles of Nutritional Assessment. Oxford University Press, Oxford.

[12] WHO Consultation on Obesity (1998) Obesity: Preventing and Managing the Global Epidemic. 
[13] Ben-Noun, L. and Laor A. (2003) Relationship of Neck Circumference to Cardiovascular Risk Factors. Obesity Research, 11, 226-231. https://doi.org/10.1038/oby.2003.35

[14] Stabe, C., Vasques, A.C.J., Lima, M.M.O., Tambascia, M.A., Pareja, J.C., Yamanaka, A., et al. (2013) Neck Circumference as a Simple Tool for Identifying the Metabolic Syndrome and Insulin Resistance: Results from the Brazilian Metabolic Syndrome Study. Clinical Endocrinology, 78, 874-881. https://doi.org/10.1111/j.1365-2265.2012.04487.x

[15] Cartolano, F.D.C., Pappiani, C., Freitas, M.C.Pd., Figueiredo Neto, A.M., Carioca, A.A.F. and Damasceno, NRT. (2018) O Produto de Acumulação Lipídica está Associado a um Perfil Aterogênico de Lipoproteínas em Indivíduos Brasileiros? Artigos Originais, 110, 339-347.

[16] Chen, B.-D., Yang, Y.-N., Ma, Y.-T., Pan, S., He, C.-H., Liu, F., et al. (2015) Waist-to-Height Ratio and Triglycerides/High-Density Lipoprotein Cholesterol Were the Optimal Predictors of Metabolic Syndrome in Uighur Men and Women in Xinjiang, China. Metabolic Syndrome and Related Disorders, 13, 214-220. https://doi.org/10.1089/met.2014.0146

[17] Chiang, J.-K., Koo, M. (2012) Lipid Accumulation Product: A Simple and Accurate Index for Predicting Metabolic Syndrome in Taiwanese People Aged 50 and Over. BMC Cardiovascular Disorders, 12, 1-6. https://doi.org/10.1186/1471-2261-12-78

[18] Cicero, A.F., D’Addato, S., Reggi, A., Reggiani, G.M., Borghi, C. (2013) Hepatic Steatosis Index and Lipid Accumulation Product as Middle-Term Predictors of Incident Metabolic Syndrome in a Large Population Sample: Data from the Brisighella Heart Study. Internal and Emergency Medicine, 8, 265-267. https://doi.org/10.1007/s11739-012-0875-9

[19] Amato, M.C., Giordano, C., Pitrone, M., Galluzzo, A. (2011) Cut-off Points of the Visceral Adiposity Index (VAI) Identifying a Visceral Adipose Dysfunction Associated with Cardiometabolic Risk in a Caucasian Sicilian Population. Lipids in Health and Disease, 10, Article No. 183. https://doi.org/10.1186/1476-511X-10-183

[20] Abruzzese, G.A., Cerrrone, G.E., Gamez, J.M., Graffigna, M.N., Belli, S., Lioy, G., et al. (2017) Lipid Accumulation Product (LAP) and Visceral Adiposity Index (VAI) as Markers of Insulin Resistance and Metabolic Associated Disturbances in Young Argentine Women with Polycystic Ovary Syndrome. Hormone and Metabolic Research, 49, 23-29. https://doi.org/10.1055/s-0042-113463

[21] Pineda, H., Castro, J., Lares, M., Huérfano, T., Brito, S. and Velasco, M.J.J.P.P.S. (2017) Lipid Accumulation Product (LAP) and Visceral Adiposity Index (VAI) a Simple and Clinically Useful Surrogate Marker for Metabolic Syndrome and Cardiovascular Disease Predictor in Non-Diabetic Venezuelan Adults. Journal of Pharma and Pharmaceutical Sciences, 2, 1-8. https://doi.org/10.24218/vjpps.2017.20

[22] İlhan, G.A., Yıldızhan, B. (2019) Visceral Adiposity Indicators as Predictors of Metabolic Syndrome in Postmenopausal Women. Clinical Investigation: Araştırma, 16, 164-168. https://doi.org/10.4274/tjod.galenos.2019.62558

[23] Rotter, I., Rył, A., Szylińska, A., Pawlukowska, W., Lubkowska, A. and Laszczyńska, M. (2017) Lipid Accumulation Product (LAP) as an Index of Metabolic and Hormonal Disorders in Aging Men. Experimental and Clinical Endocrinology \& Diabetes: Official Journal, German Society of Endocrinology [and] German Diabetes Association, 125, 176-82. https://doi.org/10.1055/s-0042-116071

[24] Guo, S.X., Zhang, X.H., Zhang, J.Y., He, J., Yan, Y.Z., Ma, J.L., et al. (2016) Visceral Adiposity and Anthropometric Indicators as Screening Tools of Metabolic Syndrome among Low Income Rural Adults in Xinjiang. Scientific Reports, 6, Article 
No. 36091. https://doi.org/10.1038/srep36091

[25] Soares, L.M. (2016) Produto de acumulação lipídica: Acurácia para identificação de portadores da síndrome metabólica em adultos. Universidade Federal de Minas Gerais, Escola de Enfermagem, Belo Horizonte. 